\title{
DROGAS E SISTEMAS CRIMINAIS: QUAL A DIFERENÇA ENTRE O USUÁRIO E O TRAFICANTE DE DROGAS PERANTE A LEGISLAÇÃO?
}

\author{
Ana Paula Lima Prudente ${ }^{1}$ \\ Carolina Gonçalves Viana Guedes ${ }^{2}$ \\ Bruno Fhilipe Amorim Lucena ${ }^{3}$ \\ Stephany Rosa Fernandes ${ }^{4}$ \\ Janaina Abreu Aguiar ${ }^{5}$ \\ Valdeci Alexandre Junior 6 \\ Felix Mateus Queiroz Diniz ${ }^{7}$ \\ João Vitor Rodrigues de Almeida ${ }^{8}$ \\ Matheus Diniz Sampaio 9 \\ João Gabriel Milhomem do Carmo ${ }^{10}$ \\ Maria Eduarda Soares Quixabeira ${ }^{11}$ \\ Renato Reis ${ }^{12}$
}

RESUMO: O artigo traz as dificuldades encontradas na jurisdição atual para estabelecer as diferenças entre usuário e traficante de drogas na legislação; e centra sua aplicação no ordenamento jurídico brasileiro, verificando-se como se dá essa aplicação através de análises em trabalhos recentes que desenvolveram informações sobre o tema. A execução dos artigos 28, caput, e do 33, caput, da Lei II.343/2006, apresentam uma norma cheia de subjetividade e complexidade, fato que causa grande insegurança jurídica. Portanto o interesse deste trabalho é verificar como se dá essa aplicação e como a interpretação das autoridades policiais é impulsor para as dificuldades encontradas inerente à aplicação da norma. Assim, a pesquisa analisa o tema, considerando a lei, os crimes, as penas e a subjetividade do $\$ 2$ O do artigo 28 , e suas controvérsias na separação de usuários e traficantes, e se os magistrados e as agências penais demonstram dificuldades em aplicar a lei de forma concreta. Além disso, faz-se uma conferição entre essas contradições e o aumento de prisioneiros no país. Portanto é analisado e descrito como esse dispositivo é subjetivo, podendo levar a contradições significativas em sua interpretação. Nessa etapa, o trabalho se propõe a entender e estudar como o aumento do número de encarcerados se relaciona com a interpretação disfuncional da norma.

Palavras-chaves: Traficante. Usuário. Lei II.343/2006.

\footnotetext{
${ }^{1}$ Formação acadêmica/instituição: AFYA/FESAR.

${ }^{2}$ Formação acadêmica/instituição: AFYA/FESAR;

${ }^{3}$ Formação acadêmica/instituição: AFYA/FESAR.

${ }^{4}$ Formação acadêmica/instituição: AFYA/FESAR.

${ }^{5}$ Formação acadêmica/instituição: AFYA/FESAR.

${ }^{6}$ Formação acadêmica/instituição:AFYA/FESAR.

7 Formação acadêmica/instituição: AFYA/FESAR

${ }^{8}$ Formação acadêmica/instituição:AFYA/FESAR.

9 Formação acadêmica/instituição: AFYA/FESAR.

1o Formação acadêmica/instituição:AFYA/FESAR

"Formação acadêmica/instituição: AFYA/FESAR.

${ }^{12}$ Professor orientador.
} 
ABSTRACT: The article presents the difficulties found in the current jurisdiction to establish the differences between drug users and traffickers in the legislation; and focuses its application in the Brazilian legal system, verifying how this application takes place through analyzes in recent works that developed information on the subject. The execution of articles 28, caput, and 33, caput, of Law II.343/2006, present a rule full of subjectivity and complexity, a fact that causes great legal uncertainty. Therefore, the interest of this work is to verify how this application takes place and how the interpretation of police authorities is a driving force for the difficulties inherent to the application of the rule. Thus, the research analyzes the subject, considering the law, crimes, penalties and subjectivity of $\$ 2$ of article 28 , and their controversies in the separation of users and traffickers, and whether magistrates and criminal agencies show difficulties in applying the law in concrete form. Furthermore, there is a check between these contradictions and the increase in the number of prisoners in the country. Therefore, it is analyzed and described how this device is subjective, which can lead to significant contradictions in its interpretation. At this stage, the work aims to understand and study how the increase in the number of prisoners is related to the dysfunctional interpretation of the rule.

Keywords: Dealer. User. Law II.343/2006.

\section{INTRODUÇÃO}

É evidente que a nossa legislação, mesmo punindo de forma diferente o usuário de drogas e o traficante, conforme os artigos 28 e 33 da Lei Ir.343/2006, não definiu critérios objetivos para que fosse realizada a sua diferenciação. Vale ressaltar ainda que o artigo 33 da Lei $\mathrm{n}^{\mathrm{o}}$ Ir.343/2006, o qual define a conduta de tráfico de drogas, é profundamente genérico, prevendo todas as condutas imagináveis que possam envolver drogas. Ainda assim, a lei prenuncia alguns critérios para a diferenciação. No § $2^{\circ}$ do artigo 28 da referida lei é previsto que:

§ 2을 Para determinar se a droga destinava a consumo pessoal, o juiz atenderá à natureza e à quantidade da substância apreendida, ao local e às condições em que se desenvolveu a ação, às circunstâncias sociais e pessoais, bem como à conduta e aos antecedentes do agente".

Desse modo, diante dos critérios vagos estabelecidos pela legislação, a jurisprudência passou a adotar uma espécie de sistema de avaliação próprio. a qual exige uma análise de todas as peculiaridades de cada caso concreto. Assim, apesar de alguns dos critérios parecerem frágeis, possuem grande força probatória quando somados.

Sendo assim, este trabalho tem como objetivo analisar as figuras do usuário e do traficante na lei de drogas. Como também, a diferença dos critérios utilizados pelo juiz nas penas, enquadrando a norma incriminadora correta. Dessa forma, estudamos e analisamos 
as normas designadas no artigo 28 e artigo 33 da lei II.343/2006. Expondo que são semelhantes no seu princípio primário e distintos no princípio secundário.

Ressaltando que a legislação não possui fundamentos seguros para diferenciar o usuário do traficante. Além disso, a lei atual de drogas se mostra discriminatória, tanto no momento de sua criação quanto utilizada em um caso concreto. Assim, surge a necessidade da distinção entre o usuário e o traficante, para que tenha segurança jurídica e uniformidade nas decisões. A questão das drogas é um grande problema no Brasil, sendo objeto de discursões entre os diversos campos de debate, pois atinge grande parte da sociedade civil. No entanto, a lei II.343/2006 tem facilitado a intensificação da estrutura repressiva.

Ademais, é relevante abordar a evolução histórica da legislação de drogas para compreender de como expandiu a criminalidade do tráfico de drogas no Brasil. Mediante de pesquisas doutrinarias, jurisprudenciais e da concretização da problemática. Além disso, serão estudados os parâmetros utilizados pelo legislador no artigo 28 , § $2^{\circ}$ da lei de drogas para diferenciar um usuário de um traficante, sobre a perspectiva crítica que o proibicionismo provoca no sistema penal.

Por fim, o objetivo deste trabalho é demonstrar que os parâmetros de distinção de usuário e traficante adotados na legislação vigente, apresentando um olhar crítico em relação ao proibicionismo exacerbado. Constituindo uma estratégia alternativa intermediária de política criminal de drogas, situada entre o proibicionismo e os modelos alternativos.

Portanto, a metodologia utilizada para desenvolvimento do trabalho foi a revisão bibliográfica, de modo qualitativo, sendo utilizados livros, artigos científicos e a legislação de drogas, tendo por base entendimento doutrinário e jurisprudencial.

\section{OBJETIVOS}

O objetivo deste trabalho é demonstrar que os parâmetros de distinção de usuário e traficante adotados na legislação vigente, apresentando um olhar crítico em relação ao proibicionismo exacerbado. Constituindo uma estratégia alternativa intermediária de política criminal de drogas, situada entre o proibicionismo e os modelos alternativos. Como também, a diferença dos critérios utilizados pelo juiz nas penas, enquadrando a norma incriminadora correta. Dessa forma, estudamos e analisamos as normas designadas no artigo 
28 e artigo 33 da lei Ir.343/2006. Expondo que são semelhantes no seu princípio primário e distintos no princípio secundário.

\section{JUSTIFICATIVA}

O problema das drogas é um grande problema no Brasil, e é objeto de polêmica em diversos campos, pois atinge direta ou indiretamente toda a sociedade civil. Portanto, dada a sua complexidade e relevância, acolhemos a atenção e a investigação sobre as contradições

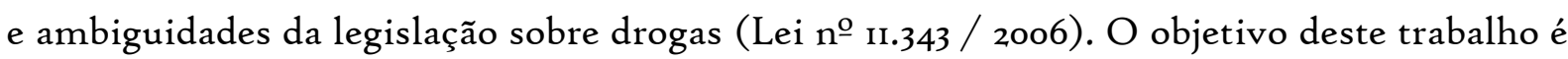
analisar a imagem do usuário e do traficante na atual legislação sobre drogas, bem como a aplicação e interpretação das normas jurídicas utilizadas pelos juízes para diferenciá-los em casos específicos. Em 27 de outubro de 2005, a Resolução no 3 do Conselho nacional de Política sobre Drogas-CONAD aprovou a Política Nacional de Drogas-PND em 27. Suas premissas incluem: "reconhecer usuários, abusadores, usuários e traficantes de drogas e tratá-los de forma diferenciada". Portanto, é necessário compreender o processo de distinção entre os crimes em questão, dadas as dúvidas e preocupações que surgem na identificação de cada crime.

\section{DROGAS E SISTEMAS CRIMINAIS}

É notório que a proibição legal da comercialização, produção e consumo de determinadas substâncias psicoativas foi uma decisão cujos contornos foram moldados na relação estabelecida entre a geopolítica e a moralidade. Qualquer substância química é capaz de acarretar alterações no corpo humano, seja ela natural ou sintética. Nesse sentido, é importante compreender os efeitos das drogas no organismo a fim de evitar a evolução dos problemas causados por elas. A hodierna política criminal de combate às drogas, ao longo do tempo, corroborou uma clara ineficiência, não obtendo a real eficiência do direito penal e não protegendo os bens jurídicos tutelados.

Diferentemente de outros delitos tradicionais como o homicídio, a criminalização do uso e do comércio de drogas é relativamente recente. As drogas ilícitas ou proibidas mais populares nos dias de hoje já eram conhecidas e consumidas pelo homem há séculos, mas seu controle penal pelo Estado somente se concretizou nas primeiras décadas do século XX, com as primeiras previsões legais de crimes e penas. É relevante ressaltar que na região 
brasileira do Acre, plantas psicoativas compõem rituais indígenas, como é o caso do uso do cipó ayahuasca na confecção de um chá alucinógeno que até hoje ainda é utilizado pela comunidade do Santo Daime.

No período colonial brasileiro, não havia uma legislação própria, eram aplicados os textos legais portugueses existentes. Efetivamente, a primeira previsão legal atinente a substâncias tóxicas com vigência no Brasil, remonta ao quinto Livro das Ordenações Filipinas. A Constituição Federal de 1988, em seu inciso XLIII do artigo $5^{\circ}$, similarmente conjeturou disposições relativas ao combate e repressão às drogas, estabelecendo a equiparação do tráfico ilícito de entorpecentes e drogas aos crimes hediondos. Desta forma, impediu a possibilidade de fiança, graça ou anistia para esses delitos, bem como determinou a responsabilização criminal dos mandantes, dos executores e dos que se omitirem quando podiam evitar essas infrações.

A redução de danos, portanto, constitui uma etapa secundária na prevenção ao uso indevido de drogas. A prevenção primária, que antecede o início da experiência de uso de drogas, busca evitar problemas decorrentes do primeiro contato com a droga que possam levar ao abuso e à dependência por 2 meio de informações, esclarecimentos, palestras e campanhas. Segundo Reghelin:

“o modelo ou estratégia preventiva de redução de danos é uma tentativa de minimização das consequências adversas do consumo de drogas, do ponto de vista da saúde e de seus aspectos sociais e econômicos sem, necessariamente, reduzir esse consumo"

A despenalização constitui uma estratégia alternativa intermediária de política criminal de drogas, situada entre o proibicionismo e os modelos alternativos, caracteriza-se pela redução das possibilidades legais de imposição de pena de prisão ao usuário de entorpecentes. Nas palavras de Caballero:

"nesse aspecto se verifica a diferença entre despenalização e legalização controlada. Esta última conserva um direito penal, mais sofisticado, menos rigoroso, e melhor adaptado à periculosidade dos produtos. Ele visa tão somente a prevenir os comportamentos antissociais, e não a impor a ordem moral”

Portanto, conclui-se que o proibicionismo acarreta maiores riscos à sociedade e à saúde pública do que protege esses mesmos fins, razão pela qual deve ser substituído por um modelo alternativo mais tolerante, humanitário e realista, além de pragmático. 


\section{I Traficante}

O uso e a comercialização de drogas é um assunto muito polêmico a ser discutido atualmente pelos diversos pensamentos da sociedade referente aos seus efeitos as pessoas. Entretanto, o uso de substância psicoativas vem bem antes do nascimento de cristo entre diferentes povos e tribos com finalidade medicinal, como a folha da coca, ópio e a maconha. No século XIX Antoine Lavoisier em suas pesquisas desenvolveu a capacidade de fracionar composto orgânicos, onde conseguiu extrair um princípio ativo de uma planta, o ópio e logo depois a cocaína da folha de coca, da onde começa a ser comercializada muito rápido na Europa e EUA pelos efeitos que libera ao usar.

Desta maneira, a primeira legislação antidrogas no Brasil surgiu em I89o no código penal republicano que no artigo 159 dizia "Expor a venda, ou ministrar, substâncias venenosas, sem legitima autorização e sem as formalidades prescritas nos regulamentos sanitários" no qual previa penas de multa, então surgi o conceito de traficante de drogas, que é um indivíduo que negocia substâncias que causam dependência, que estão disposta na portaria da ANVISA, todas as substancia que para efeitos penais são considerados drogas.

Todavia, o traficante é o indivíduo que no ato do flagrante aquele que porta quantidades excessivas para o consumo, como variedade de drogas, quantia relativa em dinheiro pela a venda do produto, caderno ou ficha que possa servi de controle financeiro da mercadoria, e o local em que ser encontra. Consequentemente o traficante tem uma má imagem perante a sociedade por suas ações, assim como leis especificas como o art. 33 da lei II.343/2006

\footnotetext{
"Importar, exportar, remeter, preparar, produzir, fabricar, adquirir, vender, expor à venda, oferecer, ter em depósito, transportar, trazer consigo, guardar, prescrever, ministrar, entregar a consumo ou fornecer drogas, ainda que gratuitamente, sem autorização ou em desacordo com determinação legal ou regulamentar”.

Pena - reclusão de 5 (cinco) a I5 (quinze) anos e pagamento de 500 (quinhentos) a I.50o (mil e quinhentos) dias-multa
}

Que determina as condições para que o ato de traficar drogas seja considerado crime. Assim como a pena que lhe é dada, bem como o art. 44 da lei Ir.343/2006;

“Os crimes previstos nos artigos 33, caput e § Io-, e 34 a 37 desta Lei são inafiançáveis e insuscetíveis de sursis, graça, indulto, anistia e liberdade provisória, vedada a conversão de suas penas em restritivas de direitos". 
Que estabelece ao traficante a restrição de direitos como a fiança, liberdade provisória, entre outros.

\subsection{Diferenças de penas}

É sabido que embora as penas para usuários e traficantes de drogas sejam diferentes, nossa legislação (arts. 28 e 33 da Lei II.343/2006)Não há critério objetivo para a distinção a ser definida.Nota-se ainda que o artigo 33 da Lei no II.343/2006, O método de definição do tráfico de drogas é muito geral, estipulando todos os comportamentos possíveis que podem envolver drogas. No entanto, a lei fornece alguns critérios para distinguir. No § $2^{\circ}$ do artigo 28 da referida lei é previsto que:

\footnotetext{
"Para determinar se a droga destinava-se a consumo pessoal, o juiz atenderá à natureza e à quantidade da substância apreendida, ao local e às condições em que se desenvolveu a ação, às circunstâncias sociais e pessoais, bem como à conduta e aos antecedentes do agente".
}

Diante dos padrões ambíguos da legislação, as súmulas passaram a adotar sistema de avaliação próprio. As condições listadas não são as únicas utilizadas. Existem outros fatores muito importantes, mas só podem ser avaliados em cada caso específico (local e hora da prisão, circunstâncias sociais e pessoais, etc.).

O artigo 33 da Lei no 11.343 / 2006 estipula o crime de tráfico de drogas, que descreve diversos atos ilícitos e proíbe qualquer forma de venda, compra, produção, armazenamento, entrega ou fornecimento, mesmo que não haja drogas ou drogas não autorizadas gratuitas. para cumprir as leis relevantes. A pena prevista é de 5 a is anos de reclusão e pagamento de multa de 500 à 1500 dias-multa, a pena básica para crimes relacionados às drogas é de cinco anos e oito meses. O juiz admitiu que A.G.P. era o réu principal com bons antecedentes, não se envolvia em atividades criminosas em tempo integral e não tinha nenhuma ligação com grupos criminosos. Dessa forma, ele poderia ter aplicado dois terços das minorias étnicas estipuladas no artigo 33, parágrafo $4^{\circ}$ da Lei no 11.343 , e reduzido sua pena para um ano e oito meses. Com esta pena, o arguido pode obter um regime semiaberto ou mesmo aberto, e utilizar a restrição de direitos em vez da restrição de liberdade. Outro ponto é o tráfico privilegiado refere-se à redução das penas estipuladas no artigo 44, parágrafo 4 da Lei Penal. Quando a pena não ultrapassar 4 anos e não houver violência ou ameaças graves, a privação de liberdade pode ser uma pena restritiva que substitui direitos. 
A mesma regra encontra-se no artigo 28 do artigo, que estipula o porte ilegal de drogas para consumo próprio. No entanto, é considerado um crime menos grave, e não há penalidades para detenção ou reclusão. Entre outras coisas, o artigo descreve a compra, guarda ou posse não autorizada de drogas, sujeita a advertências sobre as consequências do uso de entorpecentes, prestação de serviços à comunidade e participação obrigatória em programas educacionais. As características do consumo pessoal devem considerar a natureza e a quantidade do material apreendido, a forma e o local da apreensão, as circunstâncias sociais e pessoais do avaliado, seu comportamento e antecedentes criminais.

Se o acusado for menor de idade as medidas tomadas serão medidas de educação social do Artigo II2, a medida mais grave é permitir a entrada de jovens infratores nas instituições de ensino. Esta medida é especial e concisa porque restringe a liberdade de menores. $\mathrm{O}$ artigo I2I sobre a proteção de crianças e adolescentes estipula ainda que a internação não deve ultrapassar o período máximo de três anos e que os menores de 2r anos devem ser liberados. Para ser mais preciso, a análise dos crimes detidos por medidas de educação social, mais especificamente, quando um menor é detido por crime semelhante ao crime de tráfico de drogas.

\section{METODOLOGIA}

Este presente trabalho tem por finalidade trazer um desenvolvimento de pesquisar acadêmica, através de uma revisão bibliográfica de modo qualitativo baseado no material citado e outras fontes que possa complementar, como livros, artigos científicos e a legislação de drogas que traz o entendimento da lei, doutrina e jurisprudência.

Com o material citado, o trabalho a ser realizado é distinguir a diferença entre usuário e o traficante perante a legislação, no qual será feito com base em artigos científicos, no código penal e materiais da atualidade," O usuário e traficante na Lei II.343/2006: uma análise sobre os critérios distintivos", "Os critérios de distinção entre usuário e traficante estabelecidos pela lei no II.343/o6: uma análise dos impactos sociais causados pela política proibicionista", "Os critérios de diferenciação entre usuário e traficante na lei no II.343/2006”, “M.M. Afinal, é usuário ou traficante? Um estudo de caso sobre discricionariedade e ideologia da diferenciação". Diante desse material iremos extrair e 
desenvolver um trabalho apontando e esclarecendo a diferença do usuário e o traficante, além das fundamentações legislativa disposta na lei Ir.343/2006.

\section{CONCLUSÃO}

Conforme o exposto no trabalho, se torna evidente que a legislação pune aqueles indivíduos que comete ilícito relacionado a drogas, diversificando as condutas do mero usuário a de aquele que faz o tráfico. Quando se busca de forma doutrina e jurisprudencial, se adota medidas especificas para o processamento desse sistema, pois mesmo que a norma apresente critérios vagos, com a somatória de jurisprudências e entendimentos doutrinários, ganham força.

Conforme o trabalho foi possível notar que existem fatores atrelados a legislação vigente para que seja feita a distinção dentre o uso e o tráfico de drogas cometidos por agentes. Sendo possível perceber, por estudos doutrinários, a proibição que traz o Estado para com o sistema penal na política criminal de drogas.

Portanto, a política criminal em relação as drogas trazem em seu escopo a diferenciação de usuário e traficante, onde com a analise doutrinária se mostra a existência de uma política de proibição além do necessário. E com a diferenciação para o enquadramento de norma incriminadora dos artigos 28 e artigo 33 da lei II.343/2006, se faz necessário o implemento de uma estratégia para a aplicação de meios alternativos das normas.

7 CRONOGRAMA

\begin{tabular}{|c|l|l|l|l|l|l|l|l|l|l|l|}
\hline MES/ETAPAS & Mês/ano & JAN & FEV & MAR & ABRIL & MAIO & JUNHO & JULHO & AGO & $\begin{array}{l}\text { SETE } \\
\text { OUT }\end{array}$ & $\begin{array}{l}\text { OUB } \\
\text { Escolha do tema }\end{array}$ \\
\hline $\begin{array}{c}\text { Levantamento } \\
\text { bibliográfico }\end{array}$ & & & & $\mathrm{X}$ & $\mathrm{X}$ & $\mathrm{X}$ & $\mathrm{X}$ & & & & \\
\hline $\begin{array}{c}\text { Entrega da } \\
\text { monografia }\end{array}$ & & & & & & & $\mathrm{X}$ & & & & \\
\hline
\end{tabular}




\section{BIBLIOGRAFIA}

CAMPOS, Vanessa Correia. O usuário e traficante na Lei II.343/2006: uma análise sobre os critérios distintivos. Monografia (Graduação, Direito) - Universidade Federal da Bahia, Salvador, 2018.

SATYRO, Rebeca Godoi de Medeiros. Os critérios de distinção entre usuário e traficante estabelecidos pela lei no II.343/o6: uma análise dos impactos sociais causados pela política proibicionista. Monografia (Graduação, Direito) - Universidade de Brasília, Brasília-DF, 2016.

SILVANY, Rafael Abreu. Os critérios de diferenciação entre usuário e traficante na lei no II.343/2006. Monografia (Graduação, Direito) - Faculdade Baiana de Direito, Salvador, 2013. DINU, V.C; Mello, M.M. Afinal, é usuário ou traficante? Um estudo de caso sobre discricionariedade e ideologia da diferenciação. Revista Brasileira de Direito, Passo Fundo, vol. 13, n. 2, p. 194-214, Mai.-Ago. 2017. 